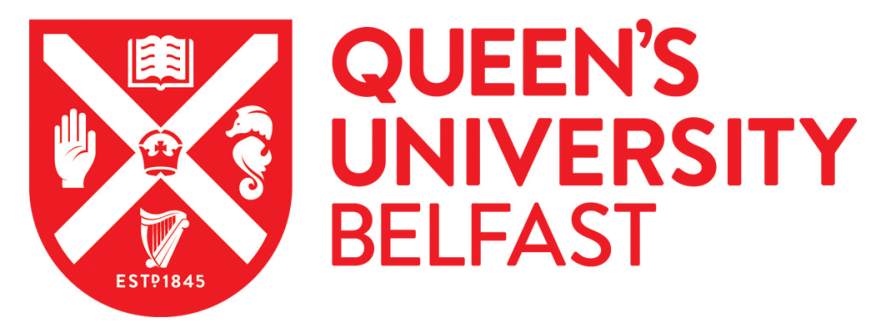

\title{
In defence of tokenism? Children's right to participate in collective decision-making
}

Lundy, L. (2018). In defence of tokenism? Children's right to participate in collective decision-making. Childhood, 25(3), 340. https://doi.org/10.1177/0907568218777292

\section{Published in: \\ Childhood}

\section{Document Version:}

Peer reviewed version

Queen's University Belfast - Research Portal:

Link to publication record in Queen's University Belfast Research Portal

Publisher rights

(C) 2018 The Authors.

This work is made available online in accordance with the publisher's policies. Please refer to any applicable terms of use of the publisher.

\section{General rights}

Copyright for the publications made accessible via the Queen's University Belfast Research Portal is retained by the author(s) and / or other copyright owners and it is a condition of accessing these publications that users recognise and abide by the legal requirements associated with these rights.

Take down policy

The Research Portal is Queen's institutional repository that provides access to Queen's research output. Every effort has been made to ensure that content in the Research Portal does not infringe any person's rights, or applicable UK laws. If you discover content in the Research Portal that you believe breaches copyright or violates any law, please contact openaccess@qub.ac.uk. 


\title{
In defence of tokenism? Implementing children's right to participate in collective decision-making.
}

\begin{abstract}
*The author would like to acknowledge the helpful comments received on earlier drafts of this paper from Grainne McKeever, Margaret Tuite and the anonymous reviewers.
\end{abstract}

\section{Introduction}

Tokenism is a dirty word in children's participation. Along with decoration and manipulation, it has been classified as a form of non-participation in decision-making (Hart, 1992) and vilified in children's rights and childhood practice and scholarship. Even though the term is not often defined, it is common parlance in child participation. It is also, seemingly, a common practice: a quarter of a century Hart ago suggested that there were 'many more instances of tokenism than there are genuine forms of children's participation in projects.' (1992: 9) and recent research suggests that little may have changed. The widely held view that tokenism does not qualify as participation has been used to justify the stance that it is better to do nothing at all than to involve children in what may amount to a tokenistic endeavour. This has been the stated position of most childhood practitioners and researchers, myself included (Lundy, 2007), and is often justified by the fact that tokenistic participation is thought to result in disaffection and disillusionment and ultimately disengagement. However, the views of children in some recent studies suggest that this is not always the case with children who have actually been involved in collective participation activities, findings that suggest a need to revisit and re-evaluate the traditional take on the role and effect of tokenism in child participation.

In international human rights law children have possessed, if not always fully enjoyed, the right to have their views given due weight for almost three decades. Article 12(1) of the UNCRC ('UNCRC' or 'the Convention') has paved the way for both individual and collective participation in decision-making (UN, 2009). This article focuses on the latter - the occasions where children's views are sought as part of a group. Given the direct and often immediate impact of decisions affecting individual children, it is difficult to sustain an argument that justifies tokenistic participation in that context. In the years since the Convention was adopted, there has been a huge increase in research exploring children's experiences of collective participation in local governance, youth and schools councils and children's parliaments, advocacy 
campaigns, service delivery and policy consultations (see generally, Percy-Smith and Thomas, 2009; Gal and Duramy, 2015).

In the last six years, the author has been involved in a series of projects that have focused on adults' and children's views and experiences of collective child participation in a wide range of global contexts. In all of the studies, many of the child participants were working with children's organizations, responding to government consultations and/or advocating for change in their own lives and those of their communities. These include, for example: the experiences of adults and children and young people engaged in children's rights advocacy in NGOs in Northern Ireland (Lundy et al, 2015a); the views of 2693 children in 71 countries on government spending, including children and young people involved in participatory budgeting initiatives (Lundy et al, 2015b); and a study of children's views on the exercise civic and political rights which included 1606 children in 60 countries (Orr et al, 2016). In each study, children were asked about their experiences of collective participation. While the children were of different ages and living in very diverse geographical, social and cultural contexts, there are striking similarities in their accounts of their experiences and perceptions of participation. With few exceptions, children report that they enjoy the participatory experience, that it develops their skills and confidence and that it raises their understanding of their rights. Equally, they often express disappointment about the fact that little account has been taken of their views and that nothing appears to have changed in spite of their engagement.

While it is rare for a child to describe his or her experience or the adults' behaviour or process using the adjective 'tokenistic', children often give accounts of having experienced adult attitudes and actions that would be classified by many as 'tokenism'. Drawing on the reported experiences of children and the adults who support them and/ or seek their views, this article revisits the concept and practice of tokenism, querying whether it is accurate to describe it as 'non-participation' and assessing the extent to which it may sometimes offer a useful step on the journey to more respectful and meaningful engagement with groups of children. Before exploring these experiences and their consequences, it is first necessary to define or at least attempt to explain what it means and how it is understood.

\section{Defining tokenism}

Despite the common use of the term 'tokenism' in the scholarship and practice of child participation, there is no one agreed definition of it. A typical dictionary definition of 'tokenism' is as follows: 'the practice of making only a perfunctory or symbolic effort to do a particular thing, especially by recruiting a small number of people from underrepresented groups in order to give the appearance of sexual or racial equality' 
(Oxford Dictionaries, 2017). Others emphasise that the term is used to imply a criticism of behaviours that are seen to be for the sake of appearance. For example, the Collins dictionary definition states that if you refer to an action as tokenism, you disapprove of it because you think it is just done for effect, in order to show a particular intention or to impress a particular type of person'(Collins Dictionary, 2017). Most definitions address the fact that tokenism refers to the inclusion or exclusion of a group of people, usually women, people with disabilities or racial minorities. In a review of a range of dictionary definitions, children are never used as an example of people who might experience tokenism.

The most frequent references to 'tokenism' in academic literature are also adultoriented, and generally found in feminist and race research. Much of the work is in the area of employment equality or organizational governance, with a significant focus placed on the numbers of the minority (such as women) needed for the group to be treated equally and to exercise influence (see, for example, the seminal work by Kanter, 1993). There are parallels with children's participation, not least in relation to whether power imbalances between adults and children might be reduced with an increased physical presence of children. However, children are additionally disadvantaged compared to the adult groups who are subjected to tokenism due to generally accepted assumptions their lack of capacity and dependency (Federle, 2017), attitudes which are no longer publicly acceptable, albeit still held by some, in relation to certain adult groups such as people with disabilities. Not only are negative assumptions about children's capacity considered to be perfectly legitimate, but the spaces and places where they seek to enter decision-making are also not the same.

A review of key literature on children's participation suggests that the term 'tokenism' is attributed to the experiences of children whose views have been sought by adults but not taken seriously. With few exceptions, the researchers who use the term are citing the seminal paper, 'Children's Participation: From Tokenism to Citizenship', written by Roger Hart for the UNICEF Innocenti Research Centre (Hart, 1992). In this paper, Hart reworked Sherry Arnstein's ladder of citizen participation (Arnstein, 1969). Hart's version for children, while used in ways that Hart did not intend (and then somewhat unfairly critiqued for others' misinterpretation) (Hart, 2008), has made an enormously valuable contribution to the understanding of good practice in child participation.

In the paper, Hart identifies three forms of non-participation, one of which is 'tokenism'. It lies above 'manipulation' and 'decoration' and below 'assigned but not informed', as the third rung from the bottom of the ladder. It is notable, but little noted, that Arnstein did not define tokenism as a form of non-participation and did not include tokenism as one of the actual rungs on the original ladder. Rather she uses 
the term to categorise three types of interaction with citizens - informing, consultation and placation (Arnstein, 1969). In contrast, Hart classifies tokenism as nonparticipation, defining it as follows: 'Tokenism is used here to describe those instances in which children are apparently given a voice, but in fact have little or no choice about the subject or the style of communicating it, and little or no opportunity to formulate their own opinions'(1992: 9). Later, reflecting on a suggestion that there should be two new rungs added to the ladder - Tolerance and Indulgence - Hart (2008) indicates that these are both elaborations of what he generally calls 'tokenism'.

Practitioners and researchers who draw on the ladder (and that includes almost everyone who has ever written anything on child participation) tend to fall into one of three groups; those who only mention the word tokenism when citing the title of Hart's paper (e.g. Thomas, 2007); those who repeat the point that tokenism is a form of non-participation (e.g. Shier, 2001); and research which suggests that children have been subject to tokenism (Invernizzi and Milne, 2002). Few engage with Hart's original definition or proffer their own. An exception to this is Tisdall (2015: 382) who describes it as follows: 'Children and young people may be consulted but their views have no discernible impact on decisions.' Examples of tokenism however abound. These include instances where children are: consulted after the decision has already been taken; allowed to speak to a limited number of less significant issues; too few in number; given insufficient time to engage meaningfully; and/or patronized or dismissed (Tisdall, 2015; Perry-Hazan, 2016).

The Committee has urged States parties to avoid tokenistic approaches defining these as those 'which limit children's expression of views, or which allow children to be heard, but fail to give their views due weight ' (UN, 2009: para. 132). This definition captures the rights-based elements of non-tokenistic participation very effectively: first children's views should not be 'limited' - the right applies to all children on all matters affecting them and second, the focus is on the serious consideration of the views and not the end result or even a lack of one. Likewise, the adults' motivation is irrelevant; some may be doing it for show, some may actually think that what they are doing is the right thing. The focus is on the actual breach of the obligation to give children's views due weight on all matters affecting them rather than the outcome or indeed the adults' intentions, benign or otherwise.

\section{Tokenism as a defense}

Child participation requires effort and resource, not least the time needed to ensure that children have access to the information they need to understand the issues and to provide support (Marshall et al, 2015; Tisdall, 2015). Since the time and resources required are rarely adequate, it is common for adult decision-makers (policy makers, 
practitioners, researchers) to exclude children on the basis that it would be tokenistic to involve them, a position that appears to confer an immunity from rebuke. If it cannot be achieved meaningfully, then it appears to be considered legitimate to not do it at all.

From a human rights perspective, this is truly striking. It is difficult to think of another situation where it would be presented as honorable to deny an individual the enjoyment of their rights on the basis that full compliance is impossible. It would be wholly unacceptable, for instance, to suggest that because there are insufficient resources to provide a good quality education that meets all of the requirements of Article 29 of the UNCRC, then no education will be given at all. The same goes for access to health care, privacy etc. Non-compliance with a human right might be justified where the right in question conflicts with another right which, in the circumstances, takes precedence. In child rights, as elsewhere, conflicts need to resolved usually by appealing to some reasonable ranking of the values at issue. So, a child might legitimately be denied their right to express their views and have them given due weight in instances where the child's participation would threaten their safety or right to life (e.g. where a televised interview complaining about drug dealers in their community leaves them a target for violent retaliation). However, in such, instances, tokenism is not the reason for non-compliance; the right to be heard is being outweighed in a conflict with another more pressing right.

One widely accepted danger of tokenistic participation is that the children will become frustrated or disillusioned and not participate in further initiatives (Bennett Woodhouse, 2003; Kirby and Bryson, 2002). Whether this is always the case will be explored further in the section that follows. However it is not in itself a legitimate excuse for inaction; a clear breach of a human rights obligation cannot be justified on the basis that it will have a negative psychological effect (such as disappointment, frustration or anger) or even that it will leave them less likely to choose to exercise the right subsequently. A human right should not be overridden by a need to protect a child's feelings, unless of course the emotional harm expected suggests a breach of another protected right (for example, it amounts to inhuman or degrading treatment). Moreover, it could be argued that, even where the children's views will not be given due weight (the critical second dimension of Article 12), the child continues to enjoy a right to freedom of expression under Article 13 (irrespective of how those views are addressed or not) and the state should be taking measures to respect, protect and fulfil that.

In summary, children may well have their time wasted and feel angry and upset that they took part in activities where they were not taken seriously and that were not fruitful for them in terms of eventual outcome. That does not in itself provide a legally 
sound or sufficient excuse for doing nothing at all. The solution is obviously to address the tokenism by providing meaningful engagement. However, there will always be situations where this is a challenge. In such instances, not only is using the defence of tokenism a poor excuse for inaction, but those who claim to be avoiding it, even in good faith, may be doing so without a full understanding of its potential value. The benefits of tokenistic participation for both children and adult decision makers, often ignored or underplayed, are explored further in the next section.

\section{In defence of tokenism?}

The negative impact of tokenism and its classification as a form of non-participation has become a truism in children's rights, unqueried by most for decades. Michael Gallagher (2008: 404) is one of the few to have questioned the dominant 'dismal' narrative around tokenism in child participation (and a separate 'ideal' narrative around democratic renewal), arguing that this appears to 'miss out something vital about the messy, fraught and ambiguous processes of children's participation.' Likewise, our findings across a number of recent research projects suggest that the consequences of tokenistic participation are not inevitably negative. Drawing on these studies, the experiences of children as rights holders ('the tokens') and adult duty-bearers ('the tokenizers') are explored below.

\section{The tokens}

Children are the prospective tokens in this context. As discussed earlier, the word itself is not usually a part of their vocabulary. Hart has observed that 'Because children are not as naive as usually assumed, they learn from such experiences that participation can be a sham' (1992: 10). Likewise, children across the research projects had a clear understanding of the instances when their participatory experiences were not genuine. When asked about their experiences of collective participation, they often recalled instances where their views were sought but they felt that they were not taken seriously. Examples given by children in one recent study on children's views on public expenditure (Lundy et al, 2015b) included the following:

It was evident that they used our participation showing up in the media. (Eastern Europe)

We tried to get an appointment with him for over a year, and not once could we go and see him, even though he told us that his office door is always open to us children. (Africa)

When asked to define good and bad participatory experiences, a group of children in Asia-Pacific described the following behaviors and attitudes. A good experience was described as follows: 
Well-informed, well-prepared, adults respect for children's voice; follow up and action of children's recommendations.

A bad experience, in contrast, included the following:

Children are invited but intimidated to speak up, disregard of children's views by adults, 'imitation' child participation, and no implementation of recommendations.

The issue is not whether children are experiencing tokenistic participation or even whether they are aware of the fact that their views have not been taken seriously they do and they know it. The significant question is what effect these experiences have on them. Much of the practice literature indicates that it will be so detrimental that they will refuse to participate again - essentially that it is a harm so great that it is to be avoided. There is also some research with children and adults that suggests the same (Stafford et al, 2003). This claim appears regularly in the student voice literature (Alderson, 2000); and may, of course, be more likely to occur in the context of schools, with one author suggesting that the consequences of tokenistic student voice 'are well documented - disaffected, cynical students; ineffectual processes; and a genuine lack of many of the potential benefits of successful participation' (Lewars: 271).

Research reporting positive reactions by children to tokenistic participation are rare. One exception is a study of children's participation in youth councils by Freeman et al (2003: 66) where one young person described their experience as follows:

It was tokenistic though, to a point. But we took it past that point when we started talking and not saying what they wanted to hear. And there's nothing wrong with tokenism for a beginning because it develops into a big hard stick that's poking them in the eye.

Our research, like that of Freeman et al, was with children who had actual and recent experience of being engaged in participatory civic action and consultations. And likewise, rather than becoming disillusioned and withdrawing from opportunities to participate in collective decision-making, many continued to advocate for change. Children gave examples of how tokenistic responses galvanised them into further action and how they often regrouped, changed tack and reformulated their approach to try again to bring about change (Orr et al, 2016):

Sometimes older people did not like what we were saying, so we went back and changed the lines of the play, but we never stopped going there. Eventually they came around. (Girl, 12, Asia-Pacific)

It needs to be acknowledged that most of the children in these studies were being supported by adult facilitators who were in a position to assist the children to reassess and try again. Many of the children identified this type of adult support as crucial. 
Nonetheless, the findings repeated across these studies challenge some of the longheld assumptions about the adverse impact of tokenistic behavior. The effect on children is not inevitably, exclusively or permanently negative.

Children also routinely report a series of ancillary benefits from their experiences of child participation, tokenistic or not. It has been argued that the personal learning that takes place is 'both an outcome and a component of the participatory process itself' and just as important as the material benefits gained (Chawla and Heft, 2002: 213). Children repeatedly report that they gain skills and confidence in the process (Davies et al, 2006). A significant element of this is the preparation and learning related to the processes or their awareness of children's rights.

I have conquered insecurities and emotions; I have made new acquaintances; I learned how to work in a group and how crucial this was and I have had fun. I think all of us have taken away something. (Child, Eastern Europe) (Orr et al, 2016)

More generally, there can be much to be gained from simply letting children into these spaces and conversations. Assuming that children will be powerless underestimates them. Gallagher, drawing on Foucault, has suggested that we should instead be asking how children 'exercise power to comply with, resist, evade, colonise, appropriate or reproduce the power exercised over them' (2008: 403). Children's capacity to exercise agency and influence can occur even when children are allowed in at 'low entry points' (Cousens, 2017: 529). Once in the dialogue (even a restricted or lop-sided one), children will gain insight into how these processes work and can harness them for their own ends. This is one example of that, in the words of a 12 year old (Orr et al, 2016):

I felt like a big person, although I'm a girl that was interviewing someone with authority to change our living conditions. Being surrounded by adult journalists, I took the floor to ask my question, attracting everyone's attention. So I took advantage to talk in the name of all children. No more violence, no more human trafficking." (Girl, 12, Latin-America-Caribbean)

In a similar vein, one young person involved in a campaign for mental health services described an event where the Minister attended the launch of some peer research, noting that: 'There was nothing he [ the government minister] could do to ignore you' especially 'if you were running that event' (Lundy et al, 2015a).

They may also simply be exercising their social and cultural capital as children and using the space for their individual ends. For example, there is criticism, including from children themselves, of youth and student councils being dominated by certain assertive and articulate children who are doing it to populate their curriculum vitae (Freeman et al, 2003). Leaving aside the fact that these children also have the right to 
be heard, there can be little doubt that the children who choose to get involved in these processes will have their own reasons and motivations and that these will not be restricted to the core goal of the process. Many decide to become involved to meet new friends, gain new skills and to have fun (Lundy et al, 2015a; Orr et al, 2016). All of this may be instead of or in addition to a desire to bring about change on the issue under consideration. These aspirations can all be achieved even when the adult response is tokenistic.

\section{The 'Tokenizers'.}

Adult decision makers are unlikely to describe themselves as tokenizers or their behavior as tokenistic yet the experiences of children outlined in multiple research projects is that they have been involved in consultations where the adults have not taken their views seriously and where the children's engagement might be accurately described as tokenistic. It is not just the perception of children and the adults who support them that participatory activity is often tokenistic. An interesting study of the experiences of children involved in the youth councils of the Israeli Knesset provides evidence of starkly tokenistic approaches from Israeli parliamentarians: a discourse analysis of the transcripts of the meetings that the young people had with politicians concluded that much of the adult engagement was 'questioning', 'fawning' or 'dismissing' (Perry-Hazan, 2016).

As with children, encounters that on the face of it might seem tokenistic can still have a positive impact, particularly where the engagement is face to face (Marshall et al, 2015). There can be significant learning to be had about good child participation even in a less than good experience. Some of the public officials who have gone ahead and engaged with children, in spite of limitations in the processes, have pointed to the learning to be had, rather than saying that they are not prepared to do it again. For example, one described the following experience:

We held sessions and actively sought young people's views but we didn't produce a children and young people's version, which was an omission. We did do that in subsequent consultations of a slightly smaller scale but we did learn the lesson to produce children's versions of the documents. We learned from that and got it better the next time. (Government representative) (Byrne and Lundy, 2011)

Decision-makers who met with children directly often speak about the positive value of these types of encounters. For example, one public official said:

In the past year for example I can think of conversations I've had with children and young people and they weren't like [consultation events]. They were proper business meetings where we sat down and talked very seriously about their situations and in those meetings I got to hear probably some of the most salient pieces of information about policy-making that I needed to... (Government representative) (Byrne and Lundy, 2011.) 
In their observations of the impact of direct meetings for the duty-bearers involved, NGOs emphasized that it gave the government officials a different but realistic insight into what the issues were for children:

I think what they would say is it's a bit of a reality check to a large degree... these guys [civil servants] are so detached at times from the reality of a child's life. It gives them a new perspective. (NGO representative) (Lundy et al, 2015a)

It was not just the different perspective, however. It was that hearing it in this way, directly from children and young people seemed to result in a shift in understanding of the issues.

As soon as they hear it from young people, somehow it's different. (NGO representative) (Lundy et al, 2015a)

Undoubtedly, this is not always the case and some adults who experience, even enact, a tokenistic form of participation may use that 'failure' to justify not ever trying it again. However, once a toe has been dipped in the waters of child participation, even if it has been imperfect or tokenistic, there is the opportunity of learning for all, including reluctant or cynical adults. Goodman and Jinks (2008) have described the positive impact of acculturation (where duty bearers comply with human rights because they know they need to be seen to be something even though they are not fully convinced of its value or legally bound to comply). They suggest that, over time, behaviour that is acculturative can be transformative with the reluctant or recalcitrant eventually becoming convinced of the value through exposure and experience, closing the gap between formal commitment and actual practice. In a similar vein, Theis has suggested that starting 'low' in child participation 'is acceptable as long as there is movement.' (2007: 529) Erstwhile tokenizers (including the author of this paper) can become future proponents.

\section{De-tokenization.}

In the preceding sections it has been argued that tokenistic forms of collective child participation can be of value to children and adults alike. However, it would clearly be preferable if children's rights were respected fully and engagement with children was not tokenistic at all. Since tokenism is the intention of the adult (what child ever goes into these processes wishing for their views to be trivialized or dismissed?) that raises the question of how to change adult attitudes and behaviours. Researchers often draw on theory and data to critique existing attempts at collective participation and then recommend the need for a 'cultural shift', often linking that to training for adults (see for example Lundy, 2007; Horgan et al, 2017). From a human rights perspective, the classic rights implementation strategies of law and education are 
obvious and common suggestions in the face of adult resistance, ignorance or indifference to human rights. It goes without saying that adults should receive training on 'skills in listening, working jointly with children and engaging children effectively in accordance with their evolving capacities' (United Nations, 2009: para. 134(g)). Children may also need their capacity built to claim their rights and this often entails the support of adults. In a study of children's civil and political rights, children spoke frequently about their need for positive, non-usurping, adults (Orr et al, 2016). Children across all of the studies provided many examples of how their adult facilitators helped them to present their views in a clear and compelling way directly to decision-makers so that they would boost their chances of being taken seriously.

Ten years ago, I suggested that we should make it 'uncomfortable for adults to solicit children and young people's opinions and then ignore them' (Lundy, 2007: 938). I settled, as others do, on the import of feedback. What was intended was a procedure that provided some transparency in the decision-making process and encouraged accountability. Children often complain that they give their views and then do not hear anything back; this conveys the message that their views were not taken seriously. Providing feedback to the children involved is thus a strategy of choice when it comes to encouraging meaningful child participation and recommended in most child participation practice guidance (see e.g. Lansdown 2011). However, there is often little detail as to what the feedback should contain, when it should happen etc. In practice, it often it takes the form of a child friendly version summarizing children's views and/ or a thank you letter. The latter has a common patter which goes as follows: 'thank you for taking the time to speak to us/ fill in the form; your views are very important to us and we will be considering them very carefully when we make our decision'. I, like many others, have been involved in drafting and distributing letters such as these, often accompanied by child-friendly summaries of a report or responses. That is the bare minimum that should happen as a matter of courtesy to the children involved. However, it seems increasingly to be a wasted opportunity to actively encourage adults to engage in a meaningful way with the substance of children's views.

Dialogue between children and adults, rather than just 'listening', has been identified as one of the most crucial dimensions of meaningful child participation (Lodge, 2005; Mannion 2007). The feedback given by adults to children at the end of a process is a pivotal point in this dialogue. From a children's rights perspective, this is when dutybearers and decision-makers get an opportunity to demonstrate to the rights-holders how they have put the 'due' in the 'due weight'. It opens up a space for further informed interaction and the possibility of continuing the dialogue. It is therefore core to accountability which is in turn core to human rights. Boosting this process could be 
a way of reducing tokenistic forms of child participation. For this to occur, it is suggested that feedback should comply with the following four "Fs".

Full: This is central to efforts to de-tokenize child participation. Responses to children where they do exist can be bland, providing little detail about the children's actual views, how they were taken seriously and what is happening (Tisdall 2015: 394). A full response would require adults to engage with the substance and explain their response. It would provide answers to questions such as: what did you agree with? What surprised you and why? What did you disagree with and why? Who is taking this forward? When will this happen and what is happening next?

Friendly (Child). Children need to be able to understand any response given to them so it needs to be made accessible to all the children who took part on any consultation exercise. There has been a significant increase in understanding the need for childfriendly summaries of the results of consultations. However, these might be confused with a feedback response unless there is an additional section that actually provides a response. Letting children know the collated results of a consultation is one thingfeedback on how their views were taken seriously is another. The response should provide a child-friendly version of the latter.

Fast. While policy processes and state decision-making are often slow, children grow up fast (Marshall et al 2015). They 'age out' of being children and will in many instances leave the institutions (schools and youth groups) where they were accessed by the adults consulting them. This underlines the need a speedy initial response effectively by return - that acknowledges their involvement, any initial progress and next steps.

Followed up. Children should not used in one-off 'smash and grabs', where decisionmakers come in, collate their views and disappear back to their offices. The encounters should be the beginning of some sort of ongoing conversation, not necessarily a life-long relationship but one that lasts for the duration of the policy and decision-making process.

Feedback is not a panacea. However, it is a distinct point in the participatory process, one that provides a unique opportunity for demonstrating transparency and further participation, both of which are crucial for social accountability. Encouraging adults to engage with the substance of children's views could lead to less superficial and more meaningful interaction. Being required to tell children why their views are overridden or how and where and when they are being implemented, could encourage adults to move a step down the road away from tokenism and towards respectful dialogue. 


\section{Conclusion}

Tokenism has become taboo and that is not without some justification. It is clearly wrong, a breach of the United Nations Convention on the Rights of the Child, for adults to encourage children to express their views if they do not give them due weight. When the decision affects an individual child, tokenistic approaches will always be wrong. When tokenistic practices occur in the context of collective participation, some children will be so disillusioned that they will disengage and some adults will cite the experience to justify not engaging with children again. However, the consequences are not always permanently or necessarily negative. Evidence suggests that children can learn from the experience; can be galvanized into further action and claim recognition in other ways; and may also just be using the opportunity for their own individual ends. Adults, even those who intend to be tokenistic, can learn from any experience of having to engage with and consult children and may end up committed to improving their efforts in the future.

It has been suggested that the most important contribution of Hart's ladder of participation is the fact that it identified the three examples of non-participation, including tokenism (Shier, 2001). This seems to me to underplay the broader value of the other rungs on ladder and the helpful categorization of different forms of participation, hierarchical or not (with 'not' being Hart's intention). Many of the popular child participation models that followed are reformulations of the higher rungs of the original. Moreover, I suggest that the categorization of tokenism as nonparticipation is not its most useful feature but an unintended flaw. There is a need for further research as to the reasons why decision-makers are reluctant to engage with children at all or directly. While we do not have evidence (other than anecdote) that some decision-makers use the defence of tokenism deliberately to avoid engagement with children, it can provide an excuse for and even an endorsement of inaction on the basis that it is considered better to do nothing at all that engage in a form of 'non-participation.'

A related concern that merits further research is whether the pressure to avoid tokenism is creating an unintended chill factor, one that excludes the very people who should be undertaking collective participation. If participation is understood by decision-makers as something complex and technical that requires a set of bespoke skills, some will react by asking others to do it on their behalf (see Byrne and Lundy, 2011; Marshall et al, 2015). This undermines the requirement that adult decisionmakers engage with children directly (UN, 2009). Participation is always imperfect: there could always be more time, more resources and more children involved. If we classify less than perfect participation as tokenistic, hence intimidating generations of 
decision-makers from attempting to engage at all or directly, then we are shutting the door to the engagement of millions of children on countless issues affecting then. Mannion (2010: 340) captures this when he suggests that in 'practising a 'warts and all' participatory approach, with all the possibilities of failure, we provide a face-valid response that may or may not work; but, critically, this is in itself empowering because it is not accepting that things are impossible.' Participation should not be rarefied to the point that it is considered unattainable. It inevitably turns on the creation of a respectful dialogue and, once children's right to be involved is accepted, ways can be found to create appropriate spaces for engagement, not all of which require a battery of expertise in creative methods, helpful and enjoyable as these can be, when time and resources permit.

In conclusion, tokenism is sometimes a start. Not listening to children's views on matters that affect them is always wrong - a breach of their human rights. Not seeking their input on the basis that it would be tokenistic is therefore also wrong. Seeking children's views and doing so in a tokenistic fashion is also wrong but arguably not as wrong as not starting at all. As always in participation, there is no one right way to do it. However, moving forward, it is submitted that it will often be better to begin a process of collective participation that could be tokenistic and then put in some checks and balances that foster a conducive environment for meaningful engagement with children's views. A starting point would a renewed focus on the significance of feedback. I suggest that there should be a requirement that the feedback provided to children is sufficiently full, appropriately child-friendly, fast and followed-up in order to create the optimal conditions for adults to engage seriously and sufficiently with the views that they have sought or been given.

\section{References:}

Arnstein S R (1969) A ladder of citizen participation. Journal of the American Institute of planners, 35(4), 216-224.

Alderson P (2000) School students' views on school councils and daily life at school. Children \& Society 14(2):121-134.

Byrne B and Lundy L (2011) Barriers to Effective Delivery for Children in Northern Ireland, Northern Ireland Commissioner for Children and Young People.

Woodhouse, B. B. (2003). Enhancing children's participation in policy formation. Arizona Law Review 45, 751-760. 
Chawla L and Heft $\mathrm{H}$ (2002) Children's competence and the ecology of communities: a functional approach to the evaluation of participation Journal of environmental psychology, 22(1-2):201-216.

Collins Dictionary. Available at:

https://www.collinsdictionary.com/dictionary/english/tokenism

(Accessed 22 September 2017).

Cousens M (2017) Child Participation in Local Governance. In Ruck Martin D., and Peterson-Badali M eds. Handbook of Children's Rights: Global and Multidisciplinary Perspectives. New York and London, Taylor \& Francis pp.515 -532.

Davies L, Williams C, Yamashita H and Ko Man-Hing A (2006) Inspiring schools: Impact and outcomes. Taking up the Challenge of Pupil Participation.

Federle K H (2017) Do Rights Still Flow Downhill? The International Journal of Children's Rights 25(2):273-284.

Freema, C, Nairn K and Sligo J (2003). 'Professionalising' Participation: From Rhetoric to Practice. Children's Geographies, 1(1), 53-70.

Gal T and Duramy B (2015) International perspectives and empirical findings on child participation: From social exclusion to child-inclusive policies. Oxford: Oxford University Press.

Gallagher M (2008) Foucault, power and participation. The International Journal of Children's Rights 16(3):395-406.

Goodman R and Jinks D (2008) incomplete internalization and compliance with human rights law European Journal of International Law 19(4):725-748.

Hart R (1992) Children's Participation: From Tokenism to Citizenship: Innocenti Essay No.4. Florence: UNICEF.

Hart R (2008) Stepping back from 'The ladder': Reflections on a model of participatory work with children. Participation and learning 19-31.

Horgan D, Forde, C, Martin S and Parkes, A (2017).Children's participation: moving from the performative to the social Children's Geographies, 15(3): 274-288. 
Invernizzi A and Milne B (2002) Are children entitled to contribute to international policy making? A critical view of children's participation in the international campaign for the elimination of child labour. The International Journal of Children's Rights, 10(4):403-431.

Kanter, RM (1993) Men and women of the corporation: New edition. New York: Basic Books.

Kirby, P and Bryson S (2002) Measuring the Magic?: Evaluating and Researching Young People's Participation in Public Decision Making. Carnegie Young People Initiative.

Lansdown G (2011) Every child's right to be heard: a resource guide on the UN committee on the rights of the child general comment no. 12. London: Save the Children/United Nations Children's Fund.

Lewars J (2009) Nil Desperandum as long as you carpe diem. In: Percy-Smith B and Thomas N (ends) A handbook of children and young people's participation: Perspectives from theory and practice. New York and London, Routledge pp .270276

Lodge C (2005). From hearing voices to engaging in dialogue: Problematising student participation in school improvement. Journal of Educational Change, 6(2), pp.125146.

Lundy L (2007). 'Voice' is not enough: conceptualising Article 12 of the United Nations Convention on the Rights of the Child. British educational research journal, 33(6), pp. 927-942.

Lundy, L, Marshall, C and Orr, K (2015a) Advancing Children's Rights through Advocacy: Capturing the learning of the Atlantic Philanthropies Grantees in Northern Ireland, The Atlantic Philanthropies.

Lundy, L, Orr, K and Marshall, C (2015b)Towards better investment in the rights of the Child: the views of children, Plan International.

Marshall C, Byrne B, Lundy L (2015) Face to face: children and young people's right to participate in public decision-making. In International Perspectives and Empirical Findings on Child Participation: From Social Exclusion to Child-Inclusive Policies. Oxford: Oxford University Press. 2015. pp. 357-380 
Mannion G (2007) Going spatial, going relational: Why "listening to children" and children's participation needs reframing. Discourse: studies in the cultural politics of education, 28(3), pp.405-420.

Mannion G (2010) After participation: the socio-spatial performance of intergenerational becoming. In: Percy-Smith B and Thomas N (eds) A handbook of children and young people's participation: Perspectives from theory and practice. Routledge. pp. 330-342.

Orr, K, Emerson, L, Lundy, L, Royal-Dawson, L and Jimenez, E.(2016) Enabling the Exercise of Civil and Political Rights: The Views of Children, Save the Children.

Oxford Dictionaries Available at: https://en.oxforddictionaries.com/definition/token (Accessed 22 September2017).

Percy-Smith B and Thomas N (eds) (2009) A handbook of children and young people's participation: Perspectives from theory and practice. New York and London, Routledge.

Perry-Hazan L (2016) Children's participation in national policymaking: "You're so adorable, adorable, and adorable! I'm speechless; so much fun!" Children and Youth Services Review, 67: 105-113.

Shier H (2001) Pathways to participation: Openings, opportunities and obligations Children \& society 15(2):107-117.

Stafford A, Laybourn A, Hill M and Walker M (2003), 'Having a say': children and young people talk about consultation Children \& Society 17: 361-373

Theis J (2007) Performance, Responsibility and Political decision-making: Child and Youth Participation in Southeast Asia, East Asia and the Pacific. Children Youth and Environments 17(1):1-13.

Thomas N (2007) towards a theory of children's participation The International Journal of Children's Rights 15(2): 199-218.

Tisdall EK (2015) Addressing the challenges of Children and Young People's Participation: Considering Time and Space. In: Gal T and Duramy B (2015) International perspectives and empirical findings on child participation: From social exclusion to child-inclusive policies. Oxford: Oxford University Press. Pp.381404. 
United Nations, (UN Committee on the Rights of the Child) (2009) General Comment No. 12, The Right of the Child to Be Heard (CRC/C/GC/12). Geneva: United Nations. 